\title{
Reduced lymphocyte transformation in early cancer of the breast
}

\author{
LOUISE A. KNIGHT AND WILLIAM M. DAVIDSON \\ From the Department of Haematology, King's College Hospital Medical School, London
}

SYNOPSIS The cell mediated immune response has been measured in vitro by lymphocyte trans $\frac{\Omega}{\sigma}$ formation in 53 patients with malignant tumours of the breast and an equal number of patients in the same age group operated upon for benign tumours.

The response to phytohaemagglutinin (PHA) was reduced in the patients with malignant tumours when the lymphocytes were grown either in the patient's plasma or in autologous plasma. This was observed when the response was measured both by the uptake of radioactive DNA precursor and? by autoradiography.

Reduced lymphocyte transformation was present even very early in the disease and certainly preoperatively. The reduction appeared to be even more marked in the advanced cases. An interesting finding was that the plasma from cancer patients contained a factor which reduced the PHA trans- -0 formation of lymphocytes from a healthy donor.

It is believed that deficiency of the cell mediated immune response is an important feature in patients with malignant disease. The recognition that lymphocyte transformation is a reliable in vitro test has provided a means for studying this response (Valentine and Lawrence, 1971). The aim of the present study is to investigate this deficiency and to determine its significance in relation to the progress of cancer of the breast. It is part of an extensive multidisciplinary, serial investigation of patients in a breast tumour survey. This paper gives an account of the results on 53 patients with malignant tumours and an equal number of patients in the same age group and also hospitalized with benign tumours of the breast. About half the patients had samples examined on two occasions.

\section{Methods}

\section{CULTURE FOR LYMPHOCYTE}

TRANSFORMATION

(a) Venous blood, $20 \mathrm{ml}$, is collected aseptically into a bottle containing $0.2 \mathrm{ml}$ of heparin free of preservative.

(b) Leucocyte rich plasma is sedimented by gravity or slight centrifugation.

(c) The appropriate amount of this plasma is added Received for publication 5 November 1974. to the culture medium (TC 199) to give a leucocyte concentration of $106 / \mathrm{ml}$.

(d) The medium is supplemented with $20 \%$ autologous or human serum.

(e) Phytohaemagglutinin (Wellcome, purified, PHA) is added to give a concentration of $4 \mu \mathrm{g} / \mathrm{ml}$, or pokeweed mitogen (Gibco, PWM) to give a concentration of $0.04 \mathrm{ml} / \mathrm{ml}$.

(f) The cultures are incubated at $37^{\circ} \mathrm{C}$ for 48 hours:-

(g) Tritiated thymidine ( ${ }^{3} \mathrm{HTdR}$ ) (Amersham, speci fic activity $5 \mathrm{Ci} / \mathrm{mmol}$ ) is then added to give a finals concentration of $1 \mu \mathrm{Ci} / \mathrm{ml}$.

(h) Sixty-eight hours after initiation of the cultureso Colcemid (Ciba) is added to give a final concentration of $0.6 \mu \mathrm{g} / \mathrm{ml}$.

(i) The cultures are then reincubated for four hours before processing.

2. MEASUREMENT OF RESPONSE

A portion of each culture is reserved for scintillation $\omega$ counting. The remainder is spun down, treated with a hypotonic solution $(0.75 \mathrm{M} \mathrm{KCl})$, and washed three times with fixative (1 glacial acetic acid:? 3 methanol). Slides are prepared and stained. Slides 0 from every culture are examined morphologically to 0 ensure that there has been no contamination and to $\overrightarrow{\mathbb{D}}$ assess the degree of blastic cell change and the frequency of mitosis. Duplicates are processed for 
autoradiography. These are dipped in $\mathrm{K} 5$ emulsion (Ilford) and stored for eight days. They are then developed and stained with Giemsa. The percentage of cells which have incorporated the labelled precursor is established by the examination of a total of $\mathbf{4 0 0}$ cells by two observers.

\section{COMPARISON BETWEEN TWO METHODS}

FOR SCINTILLATION COUNTING

Early in the study the cells were lysed with hyamine (1M in methanol), the temperature was raised to about $50^{\circ} \mathrm{C}$ to ensure a homogenous solution, and $10 \mathrm{ml}$ of scintillator (6g PPO, $0 \cdot 12 \mathrm{~g}$ POPOP made up to 1 litre with toluene) was added.

Later, after the acquisition of a Tri-Carb Sample oxidizer, $0.1 \mathrm{ml}$ of cell suspension, deposited on a filter paper, was incinerated in the oxidizer. The tritiated water from the combustion of each sample was collected, and the scintillator (Packard Insta-Gel) was added automatically. The disintegrations per minute $(\mathrm{d} / \mathrm{min})$ were counted in a Packard automatic liquid scintillation counter.

Before accepting the results the two methods were compared. A cell suspension was prepared by pooling cultures. This was divided into two fractions. One fraction was processed according to the hyamine technique: 10 samples gave a mean $\mathrm{d} / \mathrm{min}^{1}$ of 15315 with a standard error of $1.8 \%$. The other fraction was prepared by the oxidizer: 10 samples gave a mean d/min of 23790 with a standard error of $1.2 \%$, an increase in $\mathrm{d} / \mathrm{min}$ of $55 \%$ and a small decrease in the standard error.

Further, groups of measurements obtained with the hyamine method were repated with the oxidizer and the $\mathrm{d} / \mathrm{min}$ was found to be consistently some $50 \%$ higher. The reason probably is that using hyamine it is not easy to expose all the radioactive DNA, and also some of the components tend to come out of the solution if the samples are not

'We have chosen to use $\mathrm{d} / \mathrm{min}$ rather than $\mathrm{ct} / \mathrm{min}$ because it protects the data from variations which could be caused by changes in the settings of the scintillation counter, especially as months have elapsed between our first and last measurements. counted immediately. It appears therefore that the oxidizer method gives a better estimation of the radioactive uptake.

\section{TWENTY-FOUR HOURS' INCORPORATION OF LABELLED THYMIDINE}

A long exposure to labelled thymidine has been chosen to increase the accuracy of the results. After transformation, which takes place after 24-48 hours, the cells proliferate with a generation time of some 22 hours (Sasaki and Norman, 1966).

With a 24-hour exposure, most or all of the transformed cells will be in contact with the labelled precursor for at least a portion of their $S$ phase. This long exposure seems preferable to a short exposure in which the result obtained represents only a fraction of the total number of cells capable of DNA replication.

The amount of ${ }^{3} \mathrm{HtdR}$ thymidine originally used was $0.3 \mu \mathrm{Ci} / \mathrm{ml}$, but it was observed by autoradiography that this was insufficient, and many enlarged cells showed very few grains, and some mitotic figures were unlabelled.

After increasing the concentration of ${ }^{3} \mathrm{HTdR}$ to $1 \mu \mathrm{Ci} / \mathrm{ml}$ we checked that this did not constitute an inhibitory concentration. In the experiment the labelled cells reached $80.8 \%$ after a 24 -hour exposure as compared to $50 \%$ after a 5 -hour exposure.

\section{Results}

\section{RESPONSE TO PHA}

In patients and controls the lymphocytic response to PHA in culture medium supplemented with standard serum was measured by the uptake of ${ }^{3} \mathrm{HTdR}$ and by autoradiography (table I). The uptake of radioactive DNA precursor $(\mathrm{d} / \mathrm{min})$ was significantly smaller in the patients with malignant tumours compared with controls who had benign lesions $(\mathrm{P}<0.001)$. The percentage of cells incorporating the radioactive DNA precursor was also significantly smaller in patients with malignant tumours compared with controls $(P<0.001)$. A similar difference was

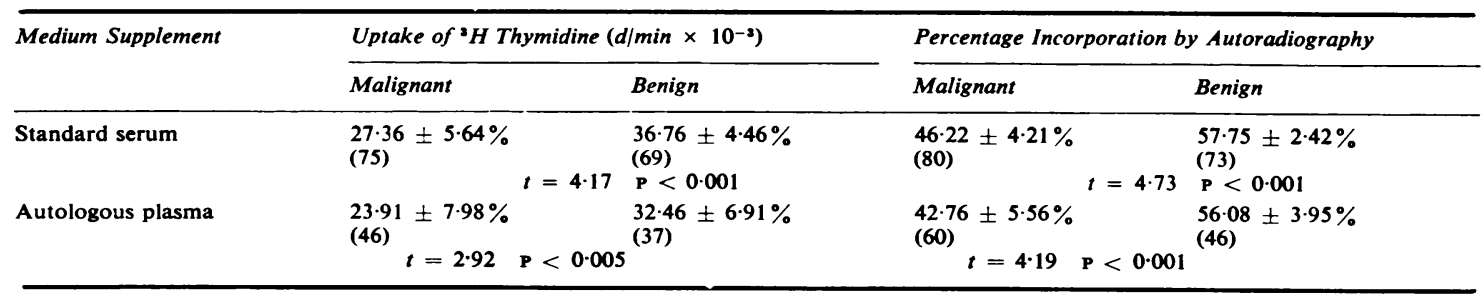

Table I Response to PHA (all patients)

Number of samples in parentheses

The figures given represent the mean \pm the standard error 
obtained when autologous plasma was used to supplement the medium $(\mathrm{P}<0.005$ for $\mathrm{d} / \mathrm{min}$ and $P<0.001$ for autoradiography).

Although the proliferative response of the lymphocytes from the patients with malignant tumours, when grown in the presence of autologous plasma, appeared to be even further reduced as compared to their response in standard serum, the difference did not reach statistical significance.

\section{RESPONSE TO POKEWEED MITOGEN (PWM)}

The level of response was noticeably lower in all cultures stimulated with PWM as compared to those stimulated with PHA. Although by both measures the response appeared to be smaller in patients with malignant tumours compared with controls (table II), the difference was not statistically significant $(P<0.2$ and $P<0.6)$.

\section{VARIATION WITH STAGE OF DISEASE}

An attempt was made to compare the proliferative response of the patients' lymphocytes at different stages of the disease, and it was found that the reduced transformation was already present in patients classified as stage I (table III) $(\mathrm{P}<0.005)$. The rate of transformation was not different in patients at stage II compared to patients at stage I. Up to the present there have been only seven patients in the study classified as stages III and IV of the disease. However, the decrease in transformation appears to be even more marked in the advanced cases.

\section{EARLY STAGE OF THE DISEASE}

In order to detect whether the reduced lymphocyte transformation is present at the time of presentation results from preoperative patients have been examined (table IV). In standard serum as well as in autologous plasma the response to PHA is diminished by both measurements in patients with malignant tumours as compared to the controls $(P<0.01(\mathrm{~d} / \mathrm{min})$ and $P<0.001$ (autoradiography) $P<0.001(\mathrm{~d} / \mathrm{min})$ and $\mathbf{P}<0.001$ (autoradiography))

5 EFFeCt OF PATIENTS' Plasma ON NORMAL LYMPHOCYTES

The response of lymphocytes from a normal donor when grown in the presence of 41 plasma samples

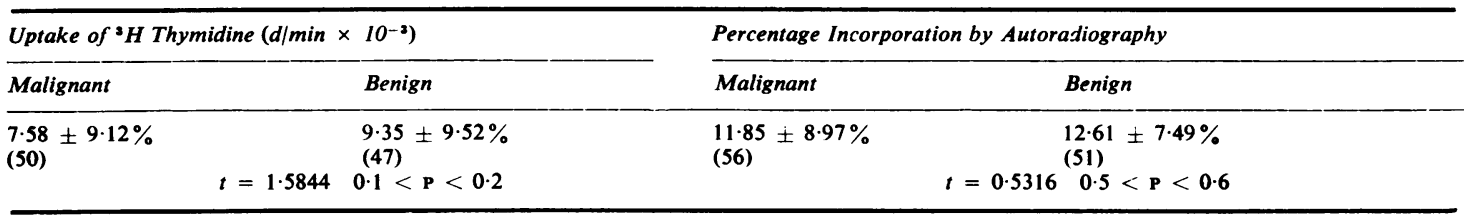

Table II Response to PWM (all patients)

See footnote to table I

\begin{tabular}{lll}
\hline Stage & Uptake of ${ }^{3} \mathrm{H}$ Thymidine $\left(d / \min \times 10^{-3}\right)$ & Percentage Incorporation by Autoradiography \\
\hline All & $27.36 \pm 5 \cdot 64 \%(75)$ & $46.22 \% \pm 4 \cdot 21 \%(80)$ \\
I & $26.59 \pm 7 \cdot 83 \%(41)$ & $45.45 \% \pm 5.54 \%(44)$ \\
II & $29.24 \pm 9 \cdot 71 \%(27)$ & $47.90 \% \pm 6.41 \%(30)$ \\
III and IV & $22.01 \pm 26.43 \%(7)$ & $38.57 \% \pm 21 \cdot 46 \%(6)$ \\
\hline
\end{tabular}

Table III Variation with stage of disease

See footnote to table I

\begin{tabular}{|c|c|c|c|c|}
\hline \multirow[t]{2}{*}{ Medium Supplement } & \multicolumn{2}{|c|}{ Uptake of ${ }^{3} \mathrm{H}$ Thymidine $\left(\mathrm{d} / \mathrm{min} \times 10^{-3}\right)$} & \multicolumn{2}{|c|}{ Percentage Incorporation by Autoradiography } \\
\hline & Malignant & Benign & Malignant & Benign \\
\hline Standard serum & $\begin{array}{l}26 \cdot 40 \pm 6 \cdot 49 \% \\
(37)\end{array}$ & $34.63 \pm 7.59 \%$ & $\begin{array}{l}47 \cdot 60 \pm 6 \cdot 16 \% \\
(39)\end{array}$ & $\begin{array}{l}60.79 \\
(33)\end{array}$ \\
\hline Autologous serum & $\begin{array}{l}21 \cdot 69 \pm 8 \cdot 16 \% \\
(20)\end{array}$ & $\begin{array}{l}7 \begin{array}{c}P<0.01 \\
33.09 \\
(16)\end{array} \\
\text { (16) }\end{array}$ & $\begin{array}{l}41.99 \\
(29)\end{array}$ & $\begin{array}{l}P<0.001 \\
59.79 \pm 5.31 \% \\
(21)\end{array}$ \\
\hline
\end{tabular}

Table IV Response to PHA (preoperative patients only)

See footnote to table I 


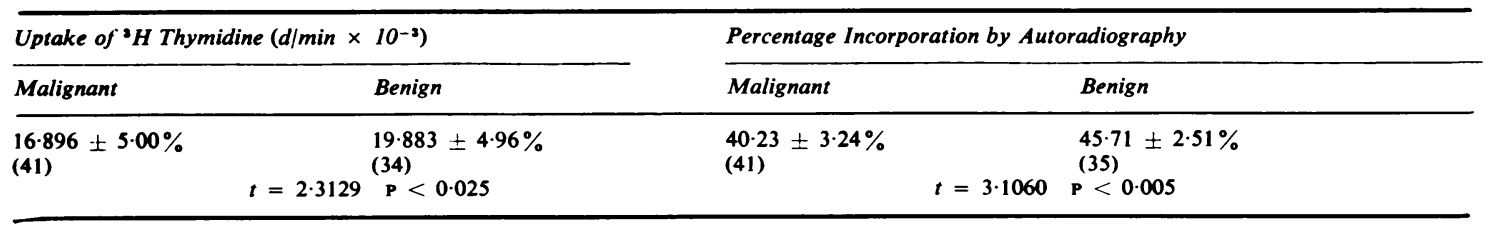

Table V Effect of patients' plasma on normal lymphocytes

See footnote to table I

from patients with malignant tumours was compared to that in the presence of 35 plasma samples from patients with benign lesions (table $\mathrm{V}$ ). The response of the normal lymphocytes was diminished $(P<$ $0.025(\mathrm{~d} / \mathrm{min})$ and $\mathrm{P}<0.005$ (autoradiography)) in the presence of plasma from patients with malignant tumours as compared to plasma from the controls.

\section{Discussion}

Depressed lymphocyte transformation has been reported in patients with a large variety of nonlymphoid malignant tumours (Gatti, 1971) and has been observed in patients with breast cancer, especially in the advanced stages (Whittaker, Rees, and Clark, 1971).

From this study it appears that lymphocyte transformation, in response to PHA, is reduced in breast cancer even very early in the disease and certainly preoperatively. This appears to be an important observation, as PHA is believed to stimulate specifically the transformation of thymus dependent small lymphocytes (Geha, Rosen, and Merler, 1974), and defective lymphocyte transformation has been correlated with an impaired immune cellular response. Stimulation by PWM is believed to activate both $\mathrm{T}$ and $\mathrm{B}$ cells (Greaves and Bauminger, 1972) but unfortunately the percentage of cells transformed is much too small so it has not been possible to decide whether there is any significant difference in the response to $B$ cells in the cancer patients.

The other interesting finding in this study is that plasma from patients with malignant tumours reduced the transformation by PHA of lymphocytes from a healthy donor. Contradictory results have been reported concerning the effect of serum from cancer patients on the PHA response of normal lymphocytes. Whittaker, Rees, and Clark (1971) obtained a reduced PHA response from normallymphocytes exposed to the serum of six patients with advanced cancer of the breast. Kumar and Taylor (1973) found that the serum from 100 patients suffering from a variety of tumours including leukaemia impaired the response of normal lymphocytes to PHA. On the other hand, Golob, Israsena, Quatrale, and Becker (1969) found no significant difference between the response of normal lymphocytes grown in cancer serum and control serum. Recently enhancement of the PHA response of normal lymphocytes in the presence of plasma obtained from patients with disseminated large bowel cancer has been reported (McIllmurray, Gray, and Langman, 1973).

Serum factors inhibiting lymphocyte transformation have also been found in a number of nonmalignant conditions (MacSween and Thomas, 1973). The nature of the inhibitors has not been fully determined. An alpha globulin fraction prepared from normal human plasma was shown to prevent homologous lymphocyte transformation by PHA (Cooperband, Bondevik, Schmid, and Mannick, 1968); a crude globulin fraction from a child suffering from fatal granulomatous disease, shown to be largely $\mathrm{IgG}$, reduced the transformation of normal lymphocytes by PHA (Barnes, Bishun, and Holliday, 1970); and a serum fraction responsible for reduced transformation of normal lymphocytes by tuberculin, reported by Scheurlen, Schneider, and Pappas (1971) in three patients with cancer and in three patients with Hodgkin's disease, was described as a (poly-) peptide. Further work is needed to identify these factors regulating the immune response and to clarify their relationship to the establishment and progress of neoplastic diseases.

We acknowledge with thanks a grant from the British Empire Cancer Campaign for Research. We are most grateful to the Faith Courtauld Unit for providing us with the blood samples. We also thank Mrs J. A. Stratton for reviewing the statistical analysis.

\section{References}

Barnes, R. D., Bishun, N. P., and Holliday, J. (1970). Impaired lymphocyte transformation and chromosomal abnormalities in fatal granulomatous disease of childhood. Acta paediat. scand., 59, 403-408.

Cooperband, S. R., Bondevik, H., Schmid, K., and Mannick, 
J. A. (1968). Transformation of human lymphocytes: inhibition by homologous alpha globulin. Science, 159, 1243-1244.

Gatti, R. A. (1971). Serum inhibitors of lymphocyte responses. (Letter). Lancet, 1, 1351-1352.

Geha, R. S., Rosen, F. S., and Merler, E. (1974). Unresponsiveness of human B lymphocytes to PHA. Nature (Lond.), 248, 426-428.

Golob, E. K., Israsena, T., Quatrale, A. C., and Becker, K. L. (1969). Effect of serum from cancer patients on homologous lymphocyte cultures. Cancer (Philad.), 23, 306-308.

Greaves, M. F. and Bauminger, S. (1972). Activation of T and B lymphocytes by insoluble phytomitogens. Nature [new Biol.], 235, 67-70.

Kumar, S. and Taylor, G. (1973). The response to phytohaemagglutinin (PHA) of lymphocytes from cancer patients. J. clin. Path., 26, 476-479.

McIllmurray, M. B., Gray, M., and Langman, M. J. S.
(1973). Effect of plasma from patients with large-bowel cancer and normal-lymphocyte responsiveness to PHA. (Letter). Lancet, 2, 452.

MacSween, R. N. M. and Thomas, M. A. (1973). Lymphocyte transformation by phytohaemagglutinin (PHA) and purified protein derivative (PPD) in primary biliary cirrhosis. Clin. exp. Immunol., 15, 523-533.

Sasaki, M. S., and Norman, A. (1966). Proliferation of human lymphocytes in culture. Nature (Lond.), 210, 913-914.

Scheurlen, P. G., Schneider, W., and Pappas, A. (1971). Inhibition of transformation of normal lymphocytes by plasma factor from patients with Hodgkin's disease and cancer. (Letter). Lancet, 2, 1265.

Valentine, F. T. and Lawrence, H. S. (1971). Cell-mediated immunity. Advanc. intern. Med., 17, 51-93.

Whittaker, M. G., Rees, K., and Clark, C. G. (1971). Reduced lymphocyte transformation in breast cancer. Lancet, 1, 892-893. 